\title{
Five centuries of Upper Indus River flow from tree rings
}

\author{
Edward R. Cook ${ }^{\mathrm{a}, *}$, Jonathan G. Palmer ${ }^{\mathrm{b}, \mathrm{c}}$, Moinuddin Ahmed ${ }^{\mathrm{d}}$, Connie A. Woodhouse ${ }^{\mathrm{e}}$, Pavla Fenwick ${ }^{\mathrm{c}}$, \\ Muhammad Usama Zafar ${ }^{\mathrm{d}}$, Muhammad Wahab ${ }^{\mathrm{d}}$, Nasrullah Khan ${ }^{\mathrm{d}}$
}

${ }^{a}$ Tree Ring Laboratory, Lamont-Doherty Earth Observatory, Columbia University, Route 9W, Palisades, NY 10964, USA

${ }^{\mathrm{b}}$ Climate Change Research Centre (CCRC), School of Biological, Earth and Environmental Sciences, The University of New South Wales, Sydney 2052, NSW, Australia

${ }^{\mathrm{c}}$ Gondwana Tree-ring Laboratory, P.O. Box 14, Little River, Canterbury 7546, New Zealand

d Botany Department, Federal Urdu University of Arts Science and Technology, Gulshan-e Iqbal, Karachi, Sind 75300, Pakistan

e School Geography and Development, University of Arizona, P.O. Box 210076, Tucson, AZ 85721, USA

\section{A R T I C L E I N F O}

\section{Article history:}

Received 29 October 2012

Received in revised form 1 February 2013

Accepted 2 February 2013

Available online $\mathrm{xxxx}$

This manuscript was handled by

Konstantine P. Georgakakos, Editor-in-Chief

\section{Keywords:}

Dendroclimatology

Upper Indus Basin discharge

Streamflow reconstruction from tree rings

Semi-parametric prediction intervals

Discharge regime shifts

\begin{abstract}
S U M M A R Y
Water wars are a prospect in coming years as nations struggle with the effects of climate change, growing water demand, and declining resources. The Indus River supplies water to the world's largest contiguous irrigation system generating $90 \%$ of the food production in Pakistan as well as 13 gigawatts of hydroelectricity. Because any gap between water supply and demand has major and far-reaching ramifications, an understanding of natural flow variability is vital - especially when only 47 years of instrumental record is available. A network of tree-ring sites from the Upper Indus Basin (UIB) was used to reconstruct river discharge levels covering the period AD 1452-2008. Novel methods tree-ring detrending based on the 'signal free' method and estimation of reconstruction uncertainty based on the 'maximum entropy bootstrap' are used. This 557-year record displays strong inter-decadal fluctuations that could not have been deduced from the short gauged record. Recent discharge levels are high but not statistically unprecedented and are likely to be associated with increased meltwater from unusually heavy prior winter snowfall. A period of prolonged below-average discharge is indicated during AD 1572-1683. This unprecedented low-flow period may have been a time of persistently below-average winter snowfall and provides a warning for future water resource planning. Our reconstruction thus helps fill the hydrological information vacuum for modeling the Hindu Kush-Karakoram-Himalayan region and is useful for planning future development of UIB water resources in an effort to close Pakistan's "water gap”. Finally, the river discharge reconstruction provides the basis for comparing past, present, and future hydrologic changes, which will be crucial for detection and attribution of hydroclimate change in the Upper Indus Basin.
\end{abstract}

(c) 2013 Elsevier B.V. All rights reserved.

\section{Introduction}

Pakistan is located in an extremely arid region, with an average rainfall of less than $240 \mathrm{~mm}$ a year making it "one of the world's most water-stressed countries" (World Bank, 2005). The rapidly growing population and economy are heavily dependent on water from the Indus River Basin to supply the largest contiguous irrigation system in the world that in turn yields $90 \%$ of the food production in Pakistan (Qureshi, 2011). The overall basin consists of six main rivers (the Indus, Jhelum, Chenab, Ravi, Sutlej, and Kabul) originating from glaciers in the Karakoram and western Himalaya. Collectively these rivers provide irrigation water to more than 16 million hectares of agricultural land and generate up to 13 gigawatts of electricity through hydropower plants in Pakistan, India, and Afghanistan (ICIMOD, 2010). Thus, as the Indus River Basin goes, so goes Pakistan.

\footnotetext{
* Corresponding author. Tel.: +1 8453658618 .

E-mail address: drdendro@ldeo.columbia.edu (E.R. Cook).
}

The Indus River itself contributes about $43 \%$ of the total annual flow of the basin, and $72 \%$ of that discharge comes from the "Northern Areas" of Pakistan (Ahmed and Joyia, 2003). The latter constitutes the Upper Indus Basin (UIB), which provides water for the storage lake behind Tarbela Dam as the river emerges from the mountains. This reservoir was primarily designed for irrigation and provides canal irrigation water for a substantial fraction of Pakistan's agricultural production. It also has an installed hydroelectric capacity of 3478 MW, which amounts to $49 \%$ of Pakistan's total hydroelectric power capacity (http://environmentdefencer.wordpress.com/tag/tarbela-dam/). So without question, adequate UIB discharge into Tarbela Reservoir is crucial to the economic and social wellbeing of the people of Pakistan.

The potential vulnerability of Pakistan to changes in UIB streamflow is indicated by recent events [or conditions]. In March 2012, the water level of Tarbela Reservoir dropped to "dead level" (http://tribune.com.pk/story/346909/water-in-tarbela-dam-touchesdead-level/), the point at which useful water yield is zero, and as of August 2012, the water level was still below normal due to 
insufficient inflow of snow and glacier meltwater into the reservoir because of below-average prior winter snows in the mountains (http://www.geo.tv/GeoDetail.aspx?ID=63047). "Dead level" may occur from time to time due to the normal seasonal drawdown of water based on irrigation and hydropower demands, but the failure of the UIB to refill the reservoir to normal levels so late in the principal runoff season is alarming. This is an example of the "water gap" between supply and demand that is increasingly facing Pakistan now (World Bank, 2005).

Thus, an obvious question is how reliable is the UIB for providing enough discharge to support both irrigation and hydropower generation needs? This is an open question because so little is known about the long-term properties of the UIB hydrologic regime and its principal contributors, snow and glacier meltwater. The most representative record of total discharge into Tarbela Reservoir is upstream at Besham and it only begins in 1969 (Archer, 2003), a short 44-year long record that is inadequate for modeling the long-term properties of river discharge (Rodriguez-Iturbe, 1969). In addition, the short streamflow records available provide no context for assessing recent trends and shifts in flow volume. These problems echo the more general concern voiced by Pellicciotti et al. (2012) over the "striking scarcity of hydro-meteorological and glaciological data" for hydrological modeling of the Hindu Kush-Karakoram-Himalayan region.
We address part of this information need through the reconstruction of UIB runoff from long, climatically sensitive, annual tree-ring chronologies in northern Pakistan. Specifically, we present a calibrated and validated reconstruction of runoff for the peak May-September discharge season for the UIB. This reconstruction extends back to 1452 C.E. As such, it provides a far more complete record of discharge variability and change over a range of timescales from annual to centennial and over a range of climate states from the early stages of the "Little Ice Age" (Gove, 1988) to the current epoch of anthropogenic climate change in the 20th and 21st centuries, referred to by some as the "Anthropocene" (Crutzen, 2002). River flow reconstructions of the kind presented here (cf., Stockton and Jacoby, 1976; Cook and Jacoby, 1983; Cleaveland, 1999; Woodhouse et al., 2006; Meko et al., 2007) have greatly increased our understanding of how discharge has varied over time in ways not possible from the relatively short gauged records that are typically available.

\section{Upper Indus Basin discharge at Partab Bridge}

The UIB discharge record at Partab Bridge $\left(34^{\circ} 43^{\prime} \mathrm{N}, 74^{\circ} 38^{\prime} \mathrm{E}\right.$; elev. 1250 m; Fig. 1; Archer, 2003) was chosen for tree-ring reconstruction because it is the longest, most representative, discharge record for the UIB. It represents $145,618 \mathrm{~km}^{2}$ or $87.7 \%$ of the

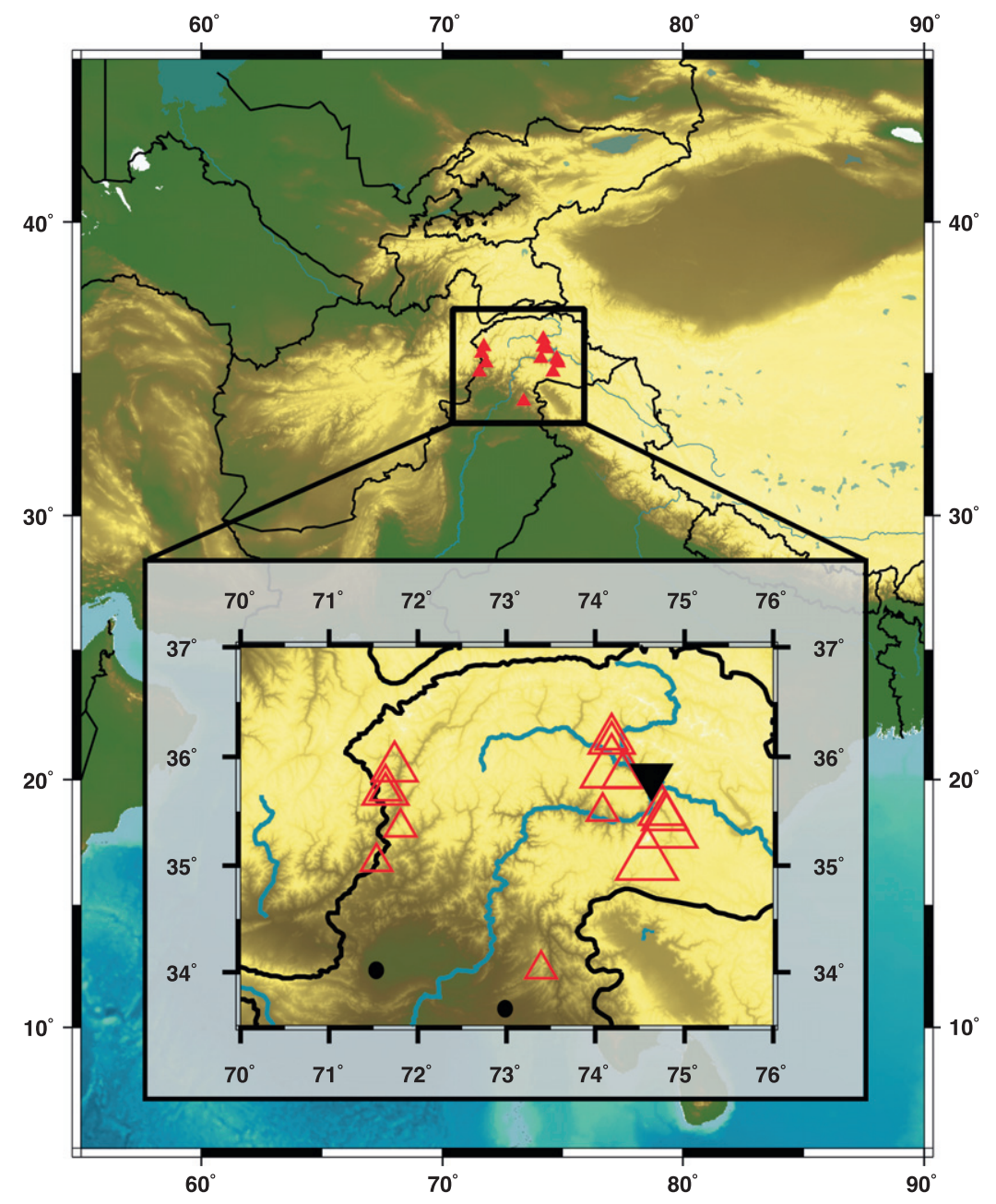

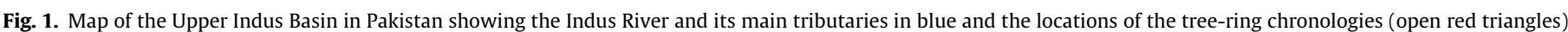

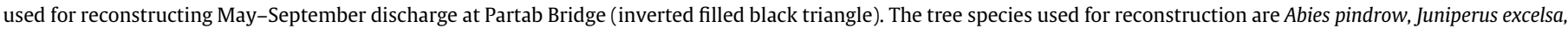

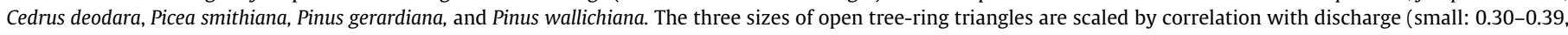

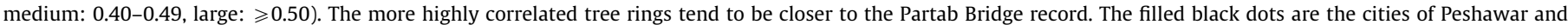

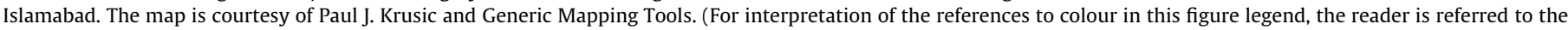
web version of this article.) 
gauged basin area draining into Tarbela Reservoir at Besham (Alford, 2011; Sharif et al., 2012) and begins in 1962, making it slightly longer than the Besham record. Monthly data for this gauge was previously made available for study by the Pakistan Water and Power Development Authority (WAPDA) for the years 1962-1996 (e.g., Archer, 2003). Subsequently, WAPDA provided us with streamflow updates to 2008 for the Indus and its major tributaries upstream from Partab Bridge, but not for Partab Bridge itself. Fortunately, these post-1996 upstream updates allowed us to usefully extend the Partab Bridge record to 2008 with a high degree of accuracy.

The specific monthly discharge records used for estimating Partab Bridge from 1997 to 2008 were:

(a) Indus River at Kachora $\left(35^{\circ} 27^{\prime} \mathrm{N}, 75^{\circ} 25^{\prime} \mathrm{E}\right)$ for $1970-2008$.

(b) Hunza River at Dainyor $\left(35^{\circ} 56^{\prime} \mathrm{N}, 7^{\circ} 23^{\prime} \mathrm{E}\right.$ ) for $1966-2008$ (missing: 2005, 2006, and 2007).

(c) Gilgit River at Gilgit $\left(35^{\circ} 56^{\prime} \mathrm{N}, 74^{\circ} 18^{\prime} \mathrm{E}\right)$ for $1960-2008$ (missing: July-December, 1999).

The sum of the mean annual flows for these gauges match the pattern of discharge at Partab Bridge very well $(r=0.96)$ for the years of overlap, 1970-1972 and 1980-1996, but with a systematic offset in mean level due to relatively minor missing discharge from other sources ( $142.6 \mathrm{~m}^{3} \mathrm{~s}^{-1}$ or $8 \%$ of mean annual flow). These results allowed us to proceed with updating the Partab Bridge monthly record to 2008. To complete the record, Indus River at Kachora monthly flows were first used to estimate the missing 6 months of data in 1999 for the Gilgit River record and the 3 years of data missing for the Hunza River. The method for estimating those missing data was based on the ratio method commonly used for estimating missing precipitation data (Chow et al., 1988), in which the missing value for a given year was estimated based on the ratio of that year's value to the average value for a gauge with complete data, along with the average for the station with the missing value. The final monthly sums of the three gauges were then adjusted to match the Partab Bridge values for the 19801996 years of overlap to account for offsets in mean level. The resulting three-gauge sum matches the flow at Partab Bridge for the years of overlap with a mean offset of only $+0.2 \%$ (Fig. 2A). The updated Partab Bridge record has a mean annual flow of $1798 \mathrm{~m}^{3} \mathrm{~s}^{-1}$ over it full period of record, which reflects $74 \%$ of the mean annual discharge into Tarbela Reservoir as measured just above it at Besham (1969-1997; no available data from 1998 to 2008). Since the two gauge records have a correlation of 0.82 over their 1969-1997 common period, we expect the variability in reconstructed flow at Partab Bridge to be broadly representative of the full UIB.

The monthly hydrograph at Partab Bridge is shown in Fig. 2B as a series of boxplots. It reveals the extreme seasonality of UIB flow recorded at this gauging station, with $85 \%$ of the mean annual discharge concentrated in the May-September period and much reduced and much less variable discharge in the other months. Thus, almost all UIB variability occurs during the warm season months, and this contributes to most of the observed interannual variability in discharge. Seasonal snow and glacier meltwater are most important here because the mean elevation of the $176,775 \mathrm{~km}^{2}$ basin above Partab Bridge is $4656 \mathrm{~m}$. This means most of the cold-season precipitation falls as snow (Hewitt, 2005) and remains on the ground until temperatures raise above freezing in the spring. Above $3500 \mathrm{~m}$, snowcover in the UIB begins disappearing in early spring and is largely gone by sometime in August (Winiger et al., 2005). But for the significantly greater area being drained above Partab Bridge, this process would be delayed in the way seen in the hydrograph. Immerzeel et al. (2009) estimated that up to $72 \%$ of all runoff in the UIB is from a combination
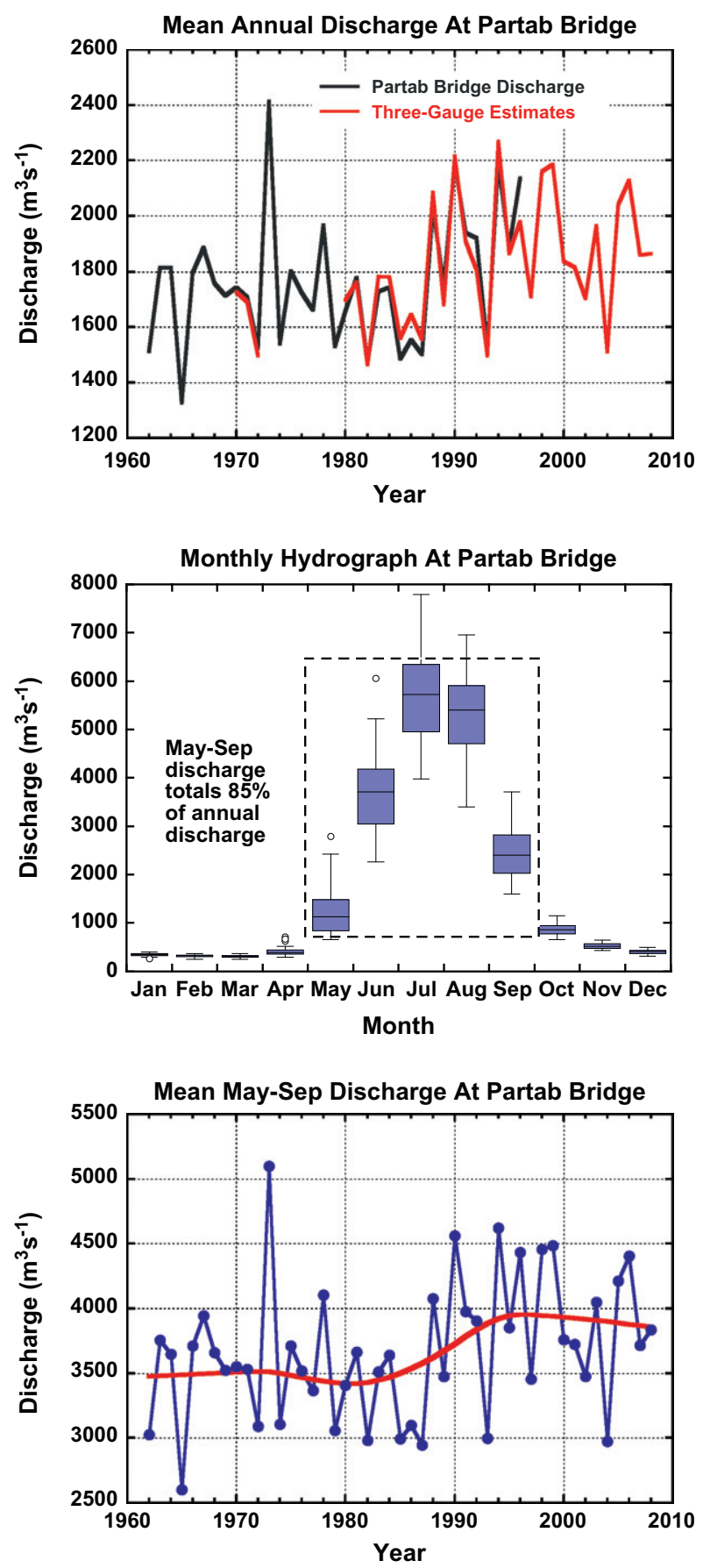

Fig. 2. The Partab Bridge discharge record for the upper Indus River since 1962. To be used, it required updating from 1997 to 2008 using the sum of three upstream records at Kachora, Hunza, and Gilgit (A). See the text for details. The estimates (red), adjusted upward for differences between the three-gauge sum and discharge at Partab Bridge, produced a very good fit in the overlap period, which justifies using those estimates as updates to 2008. The resulting monthly hydrograph (B) calculated from the updated record at Partab Bridge shows that May-September discharge accounts for $85 \%$ of the mean annual flow and almost all of its interannual variability. The May-September average discharge record (C) was consequently used for reconstruction. The red curve is a 50\% LOWESS robust smooth that highlights an apparent shift in average flow from 1987 to 1988. (For interpretation of the references to colour in this figure legend, the reader is referred to the web version of this article.)

of seasonal snow (40\%) and glacier (32\%) meltwater. Modeling experiments by Immerzeel et al. (2010) suggested an even higher (40\%) glacier meltwater contribution. In contrast, Bookhagen and Burbank (2010) estimated the annual snowmelt contribution could 
be as high as $66 \%$ in the UIB, which is more in line with an even higher estimate of $82 \%$ between late-spring snowcover area and subsequent streamflow recorded at Besham from 1969 to 1973 (Rango et al., 1977). There is clearly much uncertainty concerning the relative contributions of snow and glacier meltwater to UIB discharge.

Based on the monthly hydrograph, May-September discharge at Partab Bridge was chosen as the season to reconstruct because it encompasses most of the annual discharge and almost all of its interannual variability. Of equal importance, May-September broadly matches the extended physiologically active season of the trees used here for reconstruction. This discharge record is shown in Fig. 2C. It has a correlation of 0.996 with the mean annual series (Fig. 2A), with the same regime-like shift in discharge from 1987 to 1988 . The step-like increase in river flow since 1988 could be related to increased seasonal snowfall in the upper elevations, which has a maximum accumulation between 5000 and $6000 \mathrm{~m}$ (Hewitt, 2005), or perhaps increased glacier meltwater. At lower elevations, Archer and Fowler (2004) reported an increase in winter precipitation from 1961 to 1999 at several locations in the Karakoram range. A simple trend line fit to the discharge data from 1962 to 1999 also yields a positive trend $(r=0.33 ; p<0.05)$, which is consistent with the results of Archer and Fowler (2004). However, this trend is neither gradual nor homogeneous. Rather, it is largely driven by the abrupt jump in discharge beginning in 1988. Immerzeel et al. (2009) later used MODIS satellite measurements to construct a seasonal snow cover record from 2000 to 2008 for the UIB, which post-dates the abrupt increase in discharge. In contrast to the previous results, they found evidence for a decreasing trend in winter snow cover in two elevation zones above $4700 \mathrm{~m}$, with the highest zone above $5000 \mathrm{~m}$ having the strongest negative trend. The robust LOWESS smooth (Fig. 2C) also shows evidence for a weak negative trend in May-September discharge since 2000. Consistent with this suggestion, Shekhar et al. (2010) likewise reported a weak negative trend in Karakoram November-April snowfall since 1991/92. A similar weak trend is evident in the discharge data from 1992 to 2008. Unfortunately, none of these studies of winter precipitation change provide any insights into the cause of the jump in streamflow from 1987 to 1988.

An abrupt increase in glacier meltwater has not been considered thus far as a contributor to the jump in May-September discharge increase since 1988. The consensus opinion is that the glaciers of the Karakoram are reasonably stable (Hewitt, 2005; Schmidt and Nusser, 2009; Armstrong, 2010; Bolch et al., 2012; Gardelle et al., 2012), which implies that the glacier meltwater contribution over the 1962-2008 period has probably not increased enough to explain the increase in discharge. In addition, the Karakoram range has experienced a decreasing trend in spring/summer temperatures since the 1960s (Fowler and Archer, 2006; Shekhar et al., 2010), which argues for an actual decrease in glacier meltwater flux since 1988. In contrast, Immerzeel et al. (2009) argued that the Karakoram have in fact warmed over the past few decades. Paradoxically, their analyses are based on gridded temperature data based on some of the same station data used by Fowler and Archer (2006). Why these apparent differences exist is not clear.

Viewed in its entirety, observed May-September discharge at Partab Bridge can be interpreted in different ways. One plausible interpretation (akin to a null hypothesis here) is that warm-season UIB discharge has been experiencing natural interdecadal variability since 1962 around a relatively stationary long-term mean of $3674 \pm 77 \mathrm{~m}^{3} \mathrm{~s}^{-1}$ ( \pm 1 standard error). The data also allow for two quite different alternate hypotheses: (1) that near-normal flow occurred from 1962 to $1987\left(3470 \pm 95 \mathrm{~m}^{3} \mathrm{~s}^{-1}\right)$ followed by anomalously high flow from 1988 to $2008\left(3926 \pm 105 \mathrm{~m}^{3} \mathrm{~s}^{-1}\right)$, or (2) that anomalously low-flow occurred from 1962 to 1987 followed by a return to essentially normal flow from 1988 to 2008. Either way, a $t$-test of the difference between the two means (assuming normality, independence, and unequal variances) is statistically significant $(p<0.002)$, but the two alternate hypotheses are quite different in their hydrological interpretations. With only 47 years of UIB discharge data roughly split in half by the two putative regimes, it is impossible to say if either of these alternate hypotheses is more plausible than the null hypothesis based on all the data. The uncertainties in the statistical properties of such short hydrologic records are too large to provide useful estimates of long-term flow characteristics for modeling and simulation (RodriguezIturbe, 1969). These limitations indicate why a multi-centennial tree-ring reconstruction of UIB discharge would be so useful because it would put into long-term context the pattern of variability observed in the short Partab Bridge discharge record and provide improved estimates of its statistical properties at interdecadal and longer time scales (cf. Woodhouse et al., 2006; Meko et al., 2007).

\section{The Upper Indus Basin tree-ring network}

The high-elevation conifer forests of the UIB contain a diverse mix of tree species that can be used for reconstructions of past climate. This potential was first demonstrated by Ahmed (1989) for the Himalayan fir Abies pindrow and further documented by Esper et al. (1995) through the detailed sampling and analysis of the juniper species Juniperus excelsa in and around the Hunza Valley region of northern Pakistan. Other tree species available for sampling include Cedrus deodara, Pinus gerardiana, Pinus wallichiana and Picea smithiana (Ahmed and Sarangezai, 1991; Ahmed and Naqvi, 2005; Ahmed et al., 2011). Given this potential, and support from the Pakistan-U.S. Science and Technology Cooperation Program, a concerted effort was made to develop a dense multi-species treering network for reconstructing UIB discharge. This effort resulted in a network of 39 well-replicated annual tree-ring chronologies (see Ahmed et al., 2011), all precisely dated following standard dendrochronological cross-dating techniques (Stokes and Smiley, 1968). Of the 39 chronologies, 26 are new, including two located in far eastern Afghanistan, while the remaining 13 (all J. excelsa) are from earlier collections by Esper et al. (1995). Several species in this network have trees with ages up to $\sim 700$ years ( $C$. deodara, $P$. gerardiana, $P$. wallichiana and $P$. smithiana), but $J$. excelsa is the longest lived with some trees exceeding 1000 years of age.

The raw ringwidth measurement data for each of the 39 sites are annual records of radial tree growth measured in units of millimeters per year. As such they contain non-climatic growth trends related to biological and geometrical constraints on radial growth. These non-climatic trends are typically removed through curve fitting and detrending by a procedure called 'tree-ring standardization' (Fritts, 1976; Cook and Kairiukstis, 1990). Here, we use detrending based on the relatively new 'signal free' (SF) method (Melvin and Briffa, 2008), which is designed to enhance the preservation of common medium-frequency variance (timescales of decades to a century or more) in tree chronologies. Using the SF method, "trend distortion" effects during the detrending phase of tree-ring chronology development are eliminated. This problem is caused by the influence of common persistent medium-frequency signals (e.g. increases in growth caused by climate) on the fitting of the detrending curves. This common signal can bias the removal of supposed "non-climate" variance, leading to distortion of the external forcing signal in tree-ring chronologies (Melvin and Briffa, 2008). Trend distortion is most prevalent at the ends of the chronologies, but can occur anywhere in a tree-ring series when flexible curve fitting methods (e.g. smoothing splines; Cook 
and Peters, 1981) are used. As such, the SF method can also correct for lost common medium-frequency variance and mitigate the effects of the 'segment length curse' (Cook et al., 1995) on the preservation of variability in excess of the lengths of the tree-ring series used in chronology development. We have performed SF standardization on all of our tree-ring chronologies used for reconstruction of May-September discharge at Partab Bridge. In so doing, it is possible to evaluate the properties of UIB streamflow from interannual to centennial timescales.

Intense environmental gradients are present in the Karakoram, as indicated by Archer and Blenkinsop (2010), who found high heterogeneity between climate station data there. Correlations between the 28 site chronologies (ranging from 2450 to 3900 m.a.s.l.) were similarly investigated as a function of increasing separation distance between sites and species (Ahmed et al., 2011). A similar decline in correlation with increasing distance was consistently found both between sites of the same species and between sites composed of different species. In some cases, a much stronger correlation occurred between different species growing at the same site than between different sites of the same species, but separated by as little as $0.5 \mathrm{~km}$. Such results highlight the strong elevational gradients and highly variable slope aspects present in the Karakoram. Even so, Ahmed et al. (2011) showed through correlations between a subset of Karakoram tree rings chronologies used here and gridded monthly temperature and precipitation data over the Karakoram region that there was a strong common climate signal among the chronologies. In most cases, the chronologies correlated positively with some or all of the Januaryto-May months of precipitation preceding the growing season and negatively with some or all of the April-to-July months of temperature during the growing season. So it appears that seasonal snowfall is the primary source of soil moisture for subsequent tree growth in the Karakoram, with summertime temperature affecting radial growth through evapotranspiration demand during the photosynthetically active warm season.

Archer and Blenkinsop (2010) argued that a reconstruction of hydroclimate from tree rings in the Karakoram was unlikely to be successful because of intense environmental gradients there. As we will show, this interpretation is unduly pessimistic. The combination of a sufficiently dense and diverse multi-species tree-ring network and a well-tested statistical method for dendroclimatic reconstruction have successfully produced a skillful reconstruction of May-September discharge for the Upper Indus River at Partab Bridge covering the period 1452-2008.

\section{The streamflow reconstruction method}

For reconstruction of UIB discharge at Partab Bridge, we used a principal components regression (PCR) approach that has been used previously to reconstruct climate from tree rings (Cook et al., 1999; 2004; Cook et al., 2010a, 2010b). This approach produces a 'nested' suite of reconstructions (cf. Meko, 1997; Cook et al., 2002; Wilson et al., 2007) in which shorter tree-ring series used as predictors are sequentially eliminated from the predictor pool used in PCR until the pool is exhausted. Each of the nested reconstructions is separated by at least 10 years. The full 'nested' reconstruction is then created by appending each subset-reconstruction extension back in time to the beginning of pre-existing shorter reconstruction after appropriate scaling to recover lost variance due to regression in each reconstruction, thus producing the longest possible reconstruction from the available tree-ring data. The scaling is done to insure that no artificial variability due to differences in regression $R^{2}$ from nest to nest is present in the full nested reconstruction. The recovery of lost variance due to regression also provides for less biased comparisons of current with past climate fluctuations, but at the cost of increased uncertainty in the estimates (Ammann et al., 2010). Since changes in mean discharge are of primary interest here, this tradeoff is considered acceptable.

In developing tree-ring based reconstructions, it is important to assess model skill over the calibration period and over years that have been withheld from the calibration for model validation. For each nested subset model, a suite of calibration and validation statistics is produced., (e.g., Michaelsen, 1987; Meko, 1997; Cook et al., 1999, 2004, 2010a, 2010b): CRSQ (calibration period coefficient of multiple determination or $R^{2}$ ), CVRE (calibration period reduction of error calculated by leave-one-out cross-validation), VRSQ (validation period square of the Pearson correlation or $r^{2}$ ), VRE (validation period reduction of error) and VCE (validation period coefficient of efficiency). VRE and VCE differ from VRSQ in the way that they use the calibration and validation period means, respectively, as baselines for assessing model skill. When positive, these statistics can all be interpreted as somewhat different expressions of variance in common between the actual and estimated data. However, unlike CRSQ, which can never be negative, CVRE, VRSQ (by retaining the negative sign of $r$ after squaring), VRE and VCE can also be negative, indicating that there is no skill in the estimates. See Cook et al. $(1999,2004)$ for details. The difficulty in estimating the actual statistical significance of CVRE, VRE, and VCE even when positive has always been a problem because no theory-based tests of these statistics exist. This limitation has been largely eliminated here through the novel use of the maximum entropy bootstrap (MEBoot; Vinod, 2006; Vinod and López-de-Lacalle, 2009) to estimate reconstruction uncertainties. In so doing, nonparametric uncertainties for all of the nested calibration and validation statistics naturally emerge from the reconstruction procedure.

Besides reporting the calibration/validation statistics described above, uncertainties on the estimates themselves are also provided in the form of regression prediction intervals (Seber and Lee, 2003; Olive, 2007) estimated as:

$\hat{Y}_{f} \pm t_{n-p, 1-\alpha / 2} \sqrt{M S E} \sqrt{\left(1+h_{f}\right)}$

where $Y_{f}$ is the regression estimate, $t$ is the $1-\alpha / 2 t$-statistic with $n-$ $p$ degrees of freedom, MSE is the mean square error of the fitted calibration model, and $h_{f}$ is the "leverage" from the hat-matrix of predictors for each year calculated as:

$h_{f}=x_{f}^{T}\left(X^{T} X\right)^{-1} x_{f}$

where $\boldsymbol{X}$ is the design matrix of predictors used for calibration and $x_{f}$ is the vector of values used for prediction in year $f$. The primary difference from Eq. (1) implemented here is that the fixed $t$-statistic (assume 90\% 2-tailed limits) for scaling the uncertainties are replaced by the variable 5 th and 95 th quantiles (90\% quantile limits) from a suite of pseudo-reconstructions produced after applying MEBoot to both the predictor and predictand data prior to regression. This includes any pre-processing of the original candidate tree-ring chronologies up to the final regression model (e.g., prewhitening and predictor variable screening; cf. Cook et al., 1999). So, except for the selection of the original pool of candidate tree-ring predictors and the preprocessing that is used to create those annual tree-ring chronologies, all steps in the regression modeling procedure are incorporated in the MEBoot procedure used here. Because the fixed $t$-statistic has now been replaced by the variable nonparametric MEBoot $90 \%$ quantiles, but the overall regression-based parametric form of Eq. (1) remains intact, we refer to our uncertainties as semi-parametric prediction intervals. See Olive (2007) for alternative ways of modifying the calculation of prediction intervals to make them more general.

The maximum entropy bootstrap is distinctly different from the classical bootstrap (Efron, 1979) because it does not randomly 
sample with replacement all of the available data, or in our case, data across time. To do so would break up the temporal order of the sequence, which is a defining property of the series. In contrast, MEBoot preserves the overall shape (i.e., the temporal order) of the data, which allows for direct estimates of uncertainty to be made from the ensemble of MEBoot pseudo-reconstructions. MEBoot is also unique in the way it preserves the persistence structure and overall properties of any arbitrary stochastic process, including those that are non-stationary and heteroscedastic. This can be difficult if not impossible to do using the moving block bootstrap (cf. Wilks, 1997). In so doing, MEBoot satisfies both the ergodic theorem and central limit theorem (Vinod and López-de-Lacalle, 2009), which provides it with very nice asymptotic properties. Collectively, this guarantees that the overall stochastic properties of the original time series used in regression are well preserved in the ensemble of MEBoot pseudo-series. Thus, MEBoot adds a natural element of randomness to each pseudo-reconstruction, while preserving the overall stochastic properties of the predictor-predictand data. In this sense MEBoot can be thought of as a perturbation method. See Vinod and López-de-Lacalle (2009) for details and Vinod (2010) for a discussion on the use of MEBoot as a solution to the spurious time series regression problem.

We applied MEBoot to both the tree-ring predictors and steamflow predictand data here. This explicitly admits that there is some error on both sides of the regression model equation to consider, but these errors are either unknown or very difficult to estimate with much certainty. This makes the use of more formal 'total least squares' methods (e.g., Hegerl et al., 2007) difficult to apply because the ratio of error variances of the predictors and predictand is assumed known or at least estimated in a reasonably precise and unbiased way. In lieu of explicitly estimating these weakly constrained error variances, we use MEBoot as a perturbation method that imparts a reasonable level of random error to each series datum prior to regression modeling. This was done 300 times here (a number sufficient for $\sim 90 \%$ intervals) to produce an empirical probability density function of uncertainty for each year as a replacement for the $t$-distribution. This non-parametric part of the prediction interval equation allows the estimated uncertainties to have variable coverage from year to year and to also be asymmetric as dictated by the data. Coupling these $90 \%$ quantile uncertainties with the MEBoot 95th quantile of MSE and $h_{f}$ (the upper $90 \%$ quantile limit) for each reconstruction nest completes the estimation of the $90 \%$ semi-parametric prediction intervals.

The original parametric form of the prediction intervals in Eq. (1) has been preserved here, but it now estimates those intervals in a more non-parametric, data-adaptive way. The leverage terms can also used to identify those years that fall outside the range of the calibration period data and thus behave as extrapolations (Weisberg, 2005). In these cases, the prediction intervals are far less reliable (Olive, 2007). Also, because 300 pseudo-reconstructions have been estimated now for generating the semi-parametric prediction intervals, it follows that there are also 300 pseudo-estimates of the calibration and validation statistics described earlier for generating their $90 \%$ uncertainty intervals, including those for VRE and VCE for which there are no theory-based confidence intervals available to calculate.

\section{Tree-ring reconstruction of upper Indus River discharge}

The nested reconstruction of UIB May-September discharge was produced using the PCR approach described above. It is based on a 24 tree-ring chronology subset of the 39 available from the UIB, using only those ending on or after 2005 in order to maintain a common time interval with the Partab Bridge discharge record, The 24 tree-ring chronologies begin anywhere from 1260 to 1738 and all end on or after 2005. However, the minimum acceptable sample size for each annual mean tree-ring index value in each chronology was set to five to eliminate the more weakly replicated and least reliable inner portions of the chronologies. This resulted in a change from 1260 to 1452 for the earliest start year and from 1738 to 1800 for the latest start year.

The calibration period chosen to develop the nested regression models was 1975-2004 (30 years), with the 1962-1974 period data (13 years) withheld for independent validation of the treering estimates (cf. Fritts, 1976; Snee, 1977; Picard and Berk, 1990). The validation period is relatively short, but this limitation is compensated for in the following section by comparisons of the reconstruction to fully independent tree-ring-based hydroclimatic records from the UIB. Each chronology was evaluated for correlation with May-September discharge for both year $t$ and $t+1$ (a total of 48 candidate predictors) and only those chronologies that correlated significantly ( $p<0.10,2$-tailed) were retained as predictors in PCR (cf. Cook et al., 1999). This screening procedure reduced the predictor set from 48 candidates to 15 actually used in PCR. This included the retention of five tree species (A. pindrow, J. excelsa, C. deodara, $P$. smithiana, $P$. gerardiana, and $P$. wallichiana), with all but two being positively correlated with discharge in year $t$. The climate correlation results of Ahmed et al. (2011) suggest that these positive correlations are related to a positive response to winter-spring precipitation and the subsequent contribution of seasonal snowmelt to discharge. The geographic distribution of chronologies used, size-coded by strength of correlation with discharge, is shown in Fig. 1. It can be seen that the distribution of sites covers a large geographic portion of the Upper Indus River Ba$\sin$. The more highly correlated tree rings tend to be closer to the Partab Bridge gauging station.

The 15 screened tree-ring chronologies produced 12 nested discharge reconstructions, each created by sequentially running PCR on decreasing subsets of chronologies with progressively earlier starting years. The complete nested reconstruction (Fig. 3) extends from 1452 to 2004 (2005-08 are appended instrumental data) and the changing number of chronologies used is shown below it. The reconstruction includes the 2-tailed $90 \%$ semi-parametric prediction intervals for the reconstructed values, as described in the previous section. Below the reconstruction plot are the prediction intervals calculated two ways. One follows Eq. (1) exactly by using the parametric $t$-test to produce the $90 \%$ prediction intervals and the other uses the MEBoot reconstruction 5\% and 95\% quantiles as a replacement for the $t$-test. Only 20 -year low-pass values of each are shown for easy comparison, but they are all based on annually resolved values. The semi-parametric intervals based on MEBoot are typically wider, asymmetric, and more data driven compared to the intervals based on the $t$-statistic. In this sense, they more realistically express the uncertainties in the reconstruction and should therefore be preferred.

In terms of the model calibration and validation, the five statistics described earlier - CRSQ, CVRE for calibration and VRSQ, VRE, and VCE for validation - are listed in Table 1 as directly estimated from the actual and estimated values and as medians from the 300 nested MEBoot pseudo-reconstructions. Both versions of the statistics are positive for all nests back to 1452, which suggests that the reconstruction is valid over its entire interval. However, Fig. 4 provides a somewhat different and more complete evaluation of calibration and validation performance once the $90 \%$ quantile limits are added to the changing medians. Except for VRSQ the lower $90 \%$ limits intersect or cross below the zero line before 1480 . This result indicates that the reconstruction should be interpreted with greater caution before that year. The $90 \%$ limits are also highly assymmetric (negatively skewed) as expected given that the upper limit of each statistics is bounded by 1.0. In addition, the lower limits expand noticeably towards zero as the number of chronologies 

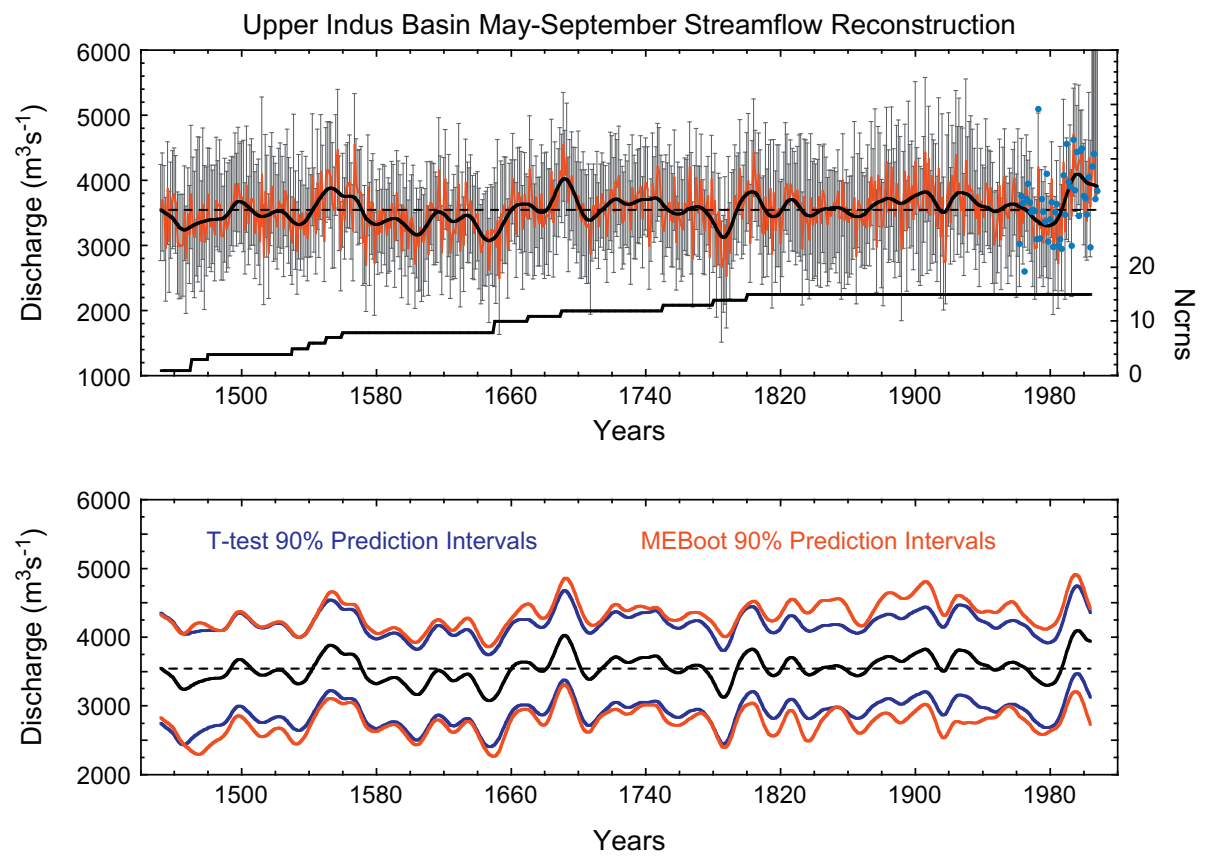

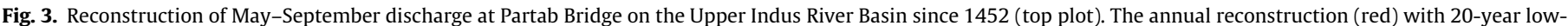

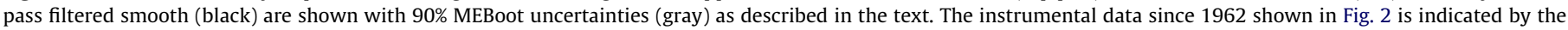

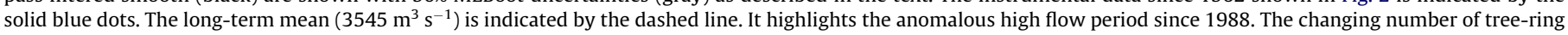

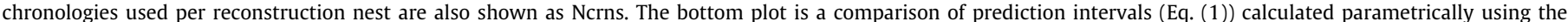

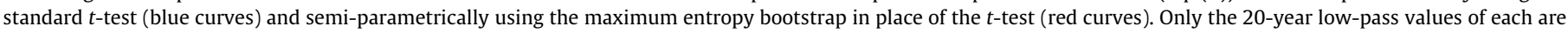

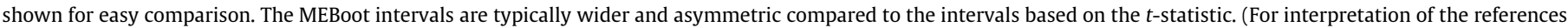
to colour in this figure legend, the reader is referred to the web version of this article.)

Table 1

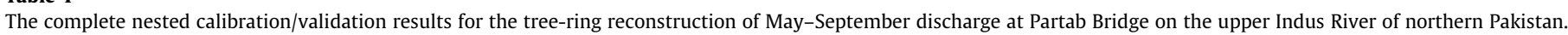

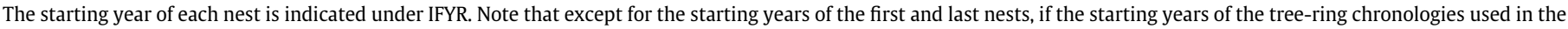

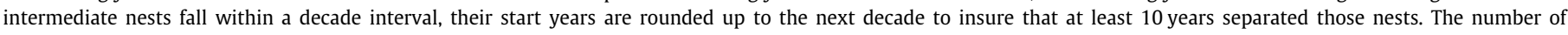

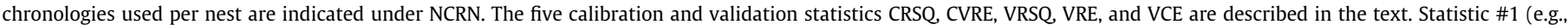

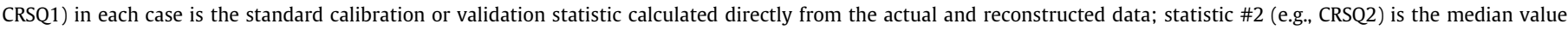

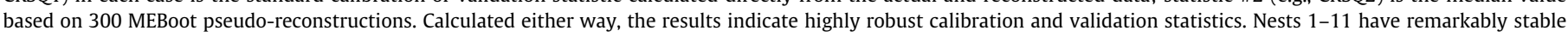

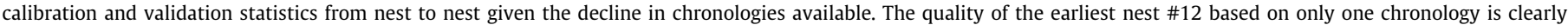
inferior to the others.

\begin{tabular}{|c|c|c|c|c|c|c|c|c|c|c|c|c|}
\hline NEST & IFYR & NCRN & CRSQ1 & CRSQ2 & CVRE1 & CVRE2 & VRSQ1 & VRSQ2 & VRE1 & VRE2 & VCE1 & VCE2 \\
\hline 1 & 1800 & 15 & 0.554 & 0.521 & 0.494 & 0.454 & 0.449 & 0.514 & 0.431 & 0.476 & 0.406 & 0.453 \\
\hline 2 & 1780 & 14 & 0.476 & 0.488 & 0.395 & 0.414 & 0.589 & 0.569 & 0.495 & 0.527 & 0.473 & 0.509 \\
\hline 3 & 1750 & 13 & 0.497 & 0.481 & 0.421 & 0.404 & 0.613 & 0.609 & 0.527 & 0.551 & 0.507 & 0.531 \\
\hline 4 & 1690 & 12 & 0.485 & 0.461 & 0.407 & 0.384 & 0.562 & 0.569 & 0.502 & 0.528 & 0.481 & 0.511 \\
\hline 5 & 1670 & 11 & 0.525 & 0.496 & 0.455 & 0.425 & 0.552 & 0.559 & 0.523 & 0.546 & 0.503 & 0.525 \\
\hline 6 & 1650 & 10 & 0.529 & 0.499 & 0.459 & 0.429 & 0.564 & 0.569 & 0.531 & 0.551 & 0.511 & 0.532 \\
\hline 7 & 1560 & 8 & 0.468 & 0.451 & 0.383 & 0.370 & 0.555 & 0.556 & 0.481 & 0.483 & 0.458 & 0.465 \\
\hline 8 & 1540 & 6 & 0.427 & 0.410 & 0.330 & 0.316 & 0.625 & 0.624 & 0.548 & 0.577 & 0.528 & 0.560 \\
\hline 9 & 1530 & 5 & 0.446 & 0.428 & 0.354 & 0.338 & 0.622 & 0.617 & 0.547 & 0.573 & 0.528 & 0.554 \\
\hline 10 & 1480 & 4 & 0.422 & 0.404 & 0.320 & 0.307 & 0.683 & 0.671 & 0.579 & 0.607 & 0.561 & 0.592 \\
\hline 11 & 1470 & 3 & 0.357 & 0.329 & 0.240 & 0.221 & 0.612 & 0.579 & 0.517 & 0.524 & 0.496 & 0.508 \\
\hline 12 & 1452 & 1 & 0.139 & 0.127 & 0.037 & 0.022 & 0.167 & 0.163 & 0.165 & 0.168 & 0.129 & 0.131 \\
\hline
\end{tabular}

used in the nests declines. This is especially evident before 1560 when the number of chronologies available drops below 10. All of these insights into calibration and validation performance have been possible through the use of the maximum entropy bootstrap.

Overall, the reconstruction calibration/validation results are significant and stable for all nests back to 1480 . This is a remarkable result given the extreme topographic complexity of the UIB and the declining number of tree-ring chronologies available for reconstruction back in time. It clearly refutes the suggestion of $\mathrm{Ar}$ cher and Blenkinsop (2010) that tree rings may not be able to reconstruct discharge in the UIB because of the topographically complex nature of the terrain there. A sufficiently dense, multi-species tree-ring network has overcome those putative barriers to provide a successful streamflow reconstruction.

\section{Comparisons with other independent records}

As strong as the calibration and validation results just presented appear to be, they still only provide information on how accurate the tree-ring estimates of streamflow are over a very restricted time period. In order to better assess the long-term accuracy and stability of the reconstruction, we compared it to three independent tree-ring-based records of hydroclimatic variability from the UIB not used in the reconstruction. These three records cover the 


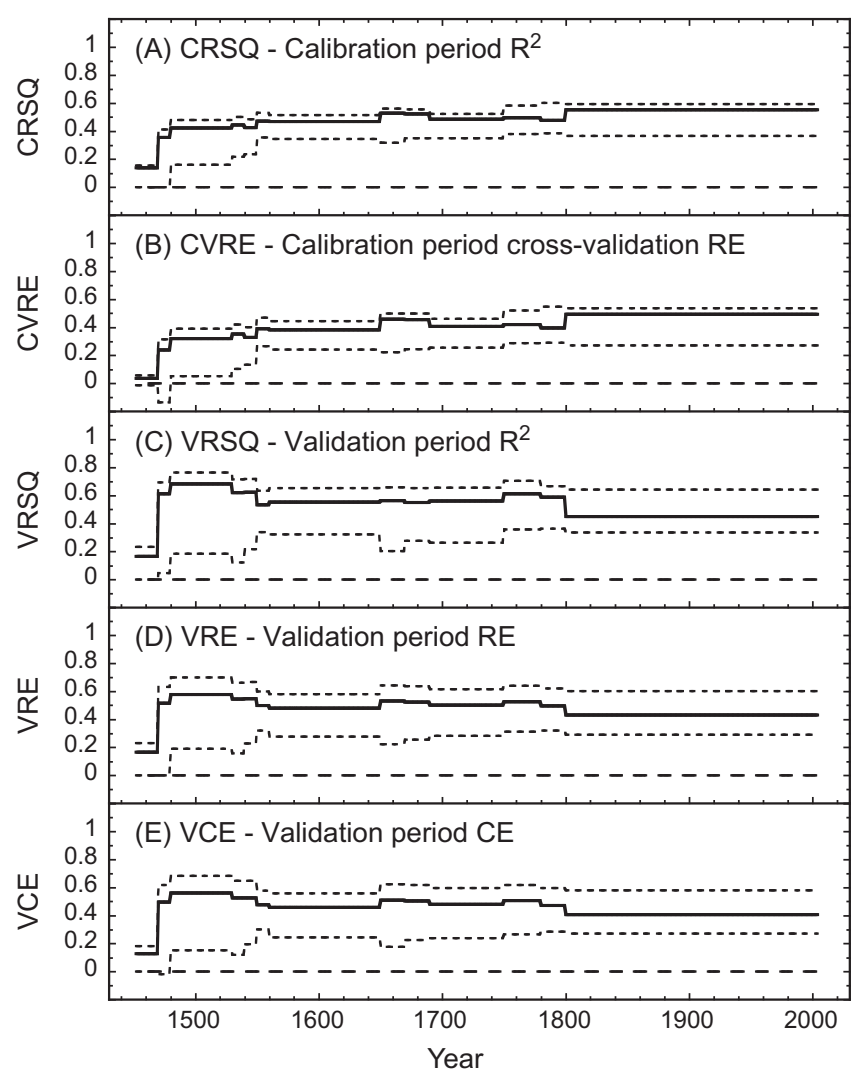

Fig. 4. Calculated calibration and validation statistics (thick solid line) and their upper and lower 90\% uncertainty quantiles (short dashes) for the calibration and validation statistics produced from 300 MEBoot pseudo-reconstructions. The changes in those statistics over time reflect changes in the chronologies used for each nested reconstruction. See the text for details. If the lower limit crosses the indicated zero line, the statistic for that nest is not significant at the $90 \%$ level.

entire span of the streamflow reconstruction back to 1452 and thus provide a complete comparison. The first series is an annually resolved oxygen isotope record from tree-ring cellulose of Juniper trees growing in the high mountains of northern Pakistan (Treydte et al., 2006). This record provides a millennium-length expression of winter precipitation variability for the UIB. As such, it indicates that the 20th century was the wettest period in northern Pakistan over the last 1000 years (Treydte et al., 2006). The other records are composites based on 16 northern Pakistan Juniper data sets developed by Esper et al. (1995), Esper et al. (2007), Esper (2000), but not used for reconstruction here because they all ended in the 1990s. These data have been pooled into high-elevation (11 sites $>3500 \mathrm{~m}$ ) and low-elevation ( 5 sites $<3500 \mathrm{~m}$ ) groups following the guidelines of Esper et al. (2007); their Table 1) and standardized using the 'signal free' method (Melvin and Briffa, 2008). Pooling the data this way allowed for a comparison of reconstructed UIB discharge and tree growth from locations that are inferred to be more temperature limited at higher elevations and more moisture limited at lower elevations (Esper et al., 2007).

Fig. 5 shows plots of the UIB discharge reconstruction (A), the Juniper oxygen isotope record (B), and the upper (C) and lower (D) elevation Juniper chronologies, all transformed into standard normal deviates for easy comparison. To facilitate this initial qualitative comparison, vertical gray bars have been added that link certain periods of reasonable visual agreement. Overall, the Esper high and low Juniper records appear to match the streamflow reconstruction a bit better than the oxygen isotope record. In order to quantitatively determine the degree to which this is true, we

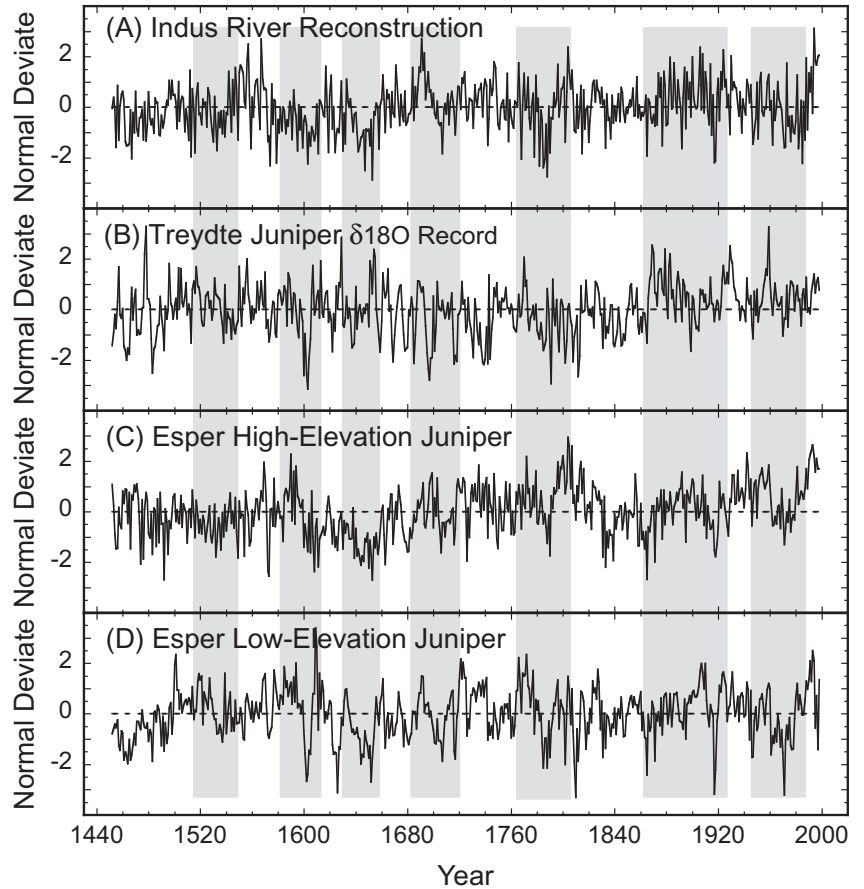

Fig. 5. Plots of the UIB discharge reconstruction (A), the Juniper oxygen isotope record (B), the upper (C) and lower (D) elevation Juniper chronologies; all transformed into standard normal deviates for easy comparison. Shaded areas indicate periods thought to contain similar response patterns.

used the Kalman filter as a dynamic regression-modeling tool (Visser and Molenaar, 1988) for the primary test of association. It uses maximum likelihood estimation to objectively test for the statistical association between reconstructed discharge and in so doing explicitly evaluate the association for the presence of time dependence. In the process, the Kalman filter also provides theory-based uncertainties. See Visser and Molenaar (1988) for details and Cook and Johnson (1989) for another example application.

Fig. 6 shows the Kalman filter results in which the UIB discharge reconstruction has been dynamically regressed on each of the test series as described above. In each case, the solid black curve shows the changing standardized regression coefficients (beta weights) and the dashed curves above and below are 2-standard error limits. Where the lower limits cross zero the beta weights are no longer considered statistically significant. For comparison to the Kalman filter results, the overall simple correlation between each pair of series is also provided. With respect to simple correlation alone, the three test series are each positively correlated $(p<0.01)$ with the UIB discharge reconstruction, but the ringwidth-based Esper series have produced the highest correlations. The signs of the correlations are also consistent with expectation: oxygen isotope variation is a direct indicator of winter precipitation and the ring-width chronologies are direct indicators of moisture availability and temperature.

The time-dependent traces of the beta weights tell a much more complete story. Most of the significant correlation between discharge and oxygen isotopes comes from the outer 200 years of record, with the earlier portion wandering in and out of significance back to 1452 . If the oxygen isotope record was the only series compared to the discharge reconstruction, it would not be possible to tell which series is the primary cause of the time dependence. However, the beta weights of the Esper high and low series show a much more stable association between discharge and Juniper ring widths, with both being significant over most of their records back to 1452 . The declines in their betas prior to about 1640 could be 
Kalman Filter Comparisons of Indus River Reconstruction to Three Independent UIB Tree-Ring Records

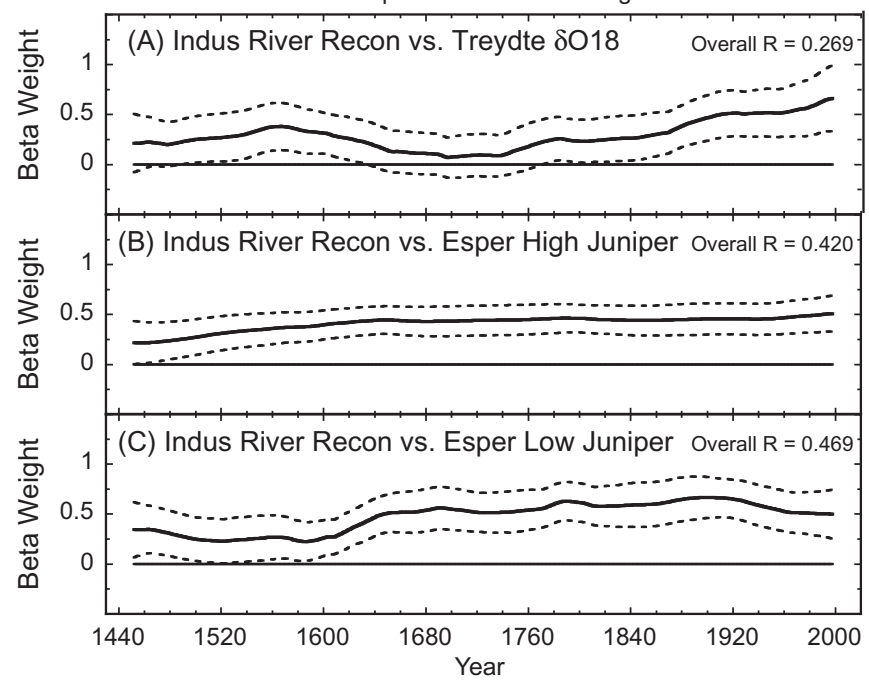

Fig. 6. Kalman filter comparisons of the Indus River reconstruction to three Juniperus UIB tree-ring records not used in the reconstruction. The Kalman filter is being used here as a dynamic regression modeling tool, which allows for the association between variables to change over time in an objectively determined manner based on maximum likelihood estimation (Visser and Molenaar, 1988). The solid black traces show how the standardized regression coefficients (beta weights) of reconstructed Indus River discharge vary when estimated by the each Juniperus series in this way. The dashed traces are \pm 2 standard error limits of the beta weights. Where the lower limits cross zero, the beta weights are not considered statistically significant at that point in time.

related to the decline in the number of chronologies used for reconstruction (Table 1). In the case of the Esper low series, the replication in that chronology also declines rapidly before that time as well (see Esper et al., 2007; their Fig. 2). Each of these replication issues is probably contributing to the estimated decline in the betas, but overall the comparisons of reconstructed discharge with the Esper high and low chronologies indicate significant stability, if not accuracy, in the reconstructed discharge values back to 1452 .

\section{Discussion}

The May-September streamflow reconstruction at Partab Bridge has many implications for the long-term runoff properties of the UIB. The long-term mean discharge estimated from the reconstruction (including the 2005-2008 instrumental-only data) is $3545 \mathrm{~m}^{3} \mathrm{~s}^{-1}$, which is below the $1962-2008$ gauged mean of $3674 \mathrm{~m}^{3} \mathrm{~s}^{-1}$ by $3.5 \%$. It is also closer to the mean for the early 1962-1987 period $\left(3470 \mathrm{~m}^{3} \mathrm{~s}^{-1}\right)$ than for the late $1988-2008$ period $\left(3926 \mathrm{~m}^{3} \mathrm{~s}^{-1}\right)$. These differences between actual and reconstructed means are unlikely to be statistically significant when the prediction interval uncertainties are factored in, but they do suggest that 1988-2008 Indus River discharge at Partab Bridge has been unusually high on average over that period nonetheless. This indication is further supported by the fact that it is necessary to go back to $1684-1700$ (mean: $3904 \mathrm{~m}^{3} \mathrm{~s}^{-1}$ ) to find a comparable high-flow period like that seen since 1988 . The reconstruction also highlights the fact that interdecadal variability on the scale seen in the observed discharge record has been a common feature of Indus river discharge since 1452 . In fact, the power spectrum of the reconstruction (not shown) has a quasi-periodic peak centered on 27 years that exceeds the $99 \%$ significance level from a red noise null continuum background. Therefore, the earlier proposed null hypothesis for natural interdecadal variability being the most likely cause of the apparent regime shift in discharge from 1987 to 1988 cannot be rejected based on the pronounced interdecadal variability in the reconstruction since 1452 .

With this in mind, the long-term reconstructed mean $\left(3545 \mathrm{~m}^{3} \mathrm{~s}^{-1}\right)$ should be used as the best estimate of expected May-September discharge at Partab Bridge in the future, but the continuation of strong interdecadal variability in the future, like that found in the past, would most likely cause multi-year departures from this expectation to occur. This statement assumes that climatic change over the UIB in the future will neither disrupt the continuation of interdecadal variability found in the past nor meaningfully increase the glacier melt water discharge component. To date, the latter does not appear to be happening if the current stable state of the Karakoram glaciers is any indication (Hewitt, 2005; Armstrong, 2010; Gardelle et al., 2012).

Perhaps the most worrying feature in the streamflow reconstruction is the occurrence of a pronounced and prolonged 112 year low-flow period from 1572 to 1683 (mean: $3377 \mathrm{~m}^{3} \mathrm{~s}^{-1}$ ) and a shorter but drier 27 year period from 1637 to 1663 (mean: $3271 \mathrm{~m}^{3} \mathrm{~s}^{-1}$ ). The former is $8.1 \%$ below and the latter $11 \%$ below the overall mean of the observed discharge record at Partab Bridge $\left(3674 \mathrm{~m}^{3} \mathrm{~s}^{-1}\right)$. Should either of these low-flow periods repeat in the future, the resulting cumulative deficit could seriously reduce Pakistan's capacity for irrigation and hydroelectric power generation provided by the Tarbela Reservoir and Dam.

Whether or not the anomalous high flow period since 1988 is from increases in seasonal snow melt or glacier melt cannot be answered definitively at this time, but the weight of the evidence leans towards the former. As discussed earlier, Karakoram glaciers are not retreating in any consistent way and in some cases are actually advancing or surging (Hewitt, 2005; Armstrong, 2010; Gardelle et al., 2012). In addition, summer temperatures over the UIB have recently decreased (Fowler and Archer, 2006; Shekhar et al., 2010), which would slow glacier melting. There is also evidence for an increase in winter and summer precipitation from 1961 to 1999 over the UIB (Archer and Fowler, 2004), which would add to summer runoff. So it is doubtful that increased glacier meltwater is the primary cause of the recent flow increase since 1988.

\section{Conclusions}

The May-September discharge reconstruction presented here is a significant contribution to our understanding of the long-term streamflow dynamics of Upper Indus River, which is primarily controlled by meltwater contributions from seasonal snowfall and glaciers. It is a well-calibrated and validated reconstruction, both by comparison to the short instrumental record and back to 1452 when compared to independent tree-ring records of past hydroclimatic variability from the same UIB region. The indicated presence of strong inter-decadal fluctuations in the reconstruction has emerged now as a common mode of hydroclimatic variability there, which could not have been deduced with any confidence from the short gauge record at Partab Bridge since 1962. This discovery further illustrates how short discharge records can severely limit our ability to statistically model hydrologic variability (Rodriguez-Iturbe, 1969). As such, the reconstruction helps fill the hydrological "data gap" for modeling the northern Pakistan part of the Hindu Kush-Karakoram-Himalayan region (Pellicciotti et al., 2012), and it should be useful to better plan for the future development of UIB water resources in an effort to close Pakistan's "water gap" (World Bank, 2005). Finally, the May-September discharge reconstruction provides the basis for comparing past, present, and future hydrologic changes, which will be crucial for detection and attribution of future hydroclimate change in the Upper Indus River Basin. At present, it appears that an observed persistant 
increase in UIB discharge from 1988 to 2008 is not statistically unprecedented and is more likely to be associated with increased meltwater from heavier prior winter snow accumulation than from enhanced summer glacier melting.

\section{Acknowledgements}

We gratefully acknowledge the help of the Pakistan Water and Power Development Authority (WAPDA), Higher Education Commission (HEC) of Pakistan, and the Pakistan Meteorological Department (PMD) in conducting our research in Pakistan. We also thank Jan Esper and Kirstin Treydte for the long Juniperus records used for comparison. Four anonymous reviewers also provided excellent suggestions that improved the paper. The authors were supported by the U.S. Agency for International Development (USAID) through NAS Grant PGA-P280423 and EC later by the U.S. Department of Energy Grant DE-SC0006616 LDE. Lamont-Doherty Earth Observatory Contribution Number 7668.

\section{References}

Ahmed, M., 1989. Tree-ring chronologies of Abies pindrow (Royle) Spach, from the Himalayan region of Pakistan. Pak. J. Bot. 21 (2), 347-354.

Ahmed, S., Joyia, M.F., 2003. NASSD Background Paper: Water. IUCN Pakistan, Northern Areas Progamme, Gilgit. 67 pp.

Ahmed, M., Naqvi, S.H., 2005. Tree-ring chronologies of Picea smithiana (Wall) Boiss. and its quantitative vegetational description from Himalayan range of Pakistan. Pak. J. Bot. 37, 697-707.

Ahmed, M., Sarangezai, A.T., 1991. Dendrochronological approach to estimate age and growth rate of various species from Himalayan region of Pakistan. Pak. J. Bot. 23, 78-89.

Ahmed, M., Palmer, J., Khan, N., Wahab, M., Fenwick, P., Esper, J., Cook, E., 2011. The dendroclimatic potential of conifers from northern Pakistan. Dendrochronologia 29, 77-88.

Alford, D., 2011. Hydrology and glaciers in the Upper Indus Basin, South Asia Sustainable Development (SASDN). South Asia Agriculture and Rural Development Unit, The World Bank, Washington, DC.

Ammann, C.M., Genton, M.G., Li, B., 2010. Technical note: correcting for signal attenuation from noisy proxy data in climate reconstructions. Clim. Past 6 (2), 273-279.

Archer, D., 2003. Contrasting hydrological regimes in the Upper Indus Basin. J. Hydrol. 274, 198-210.

Archer, D., Blenkinsop, S., 2010. Heterogeneity and spatial representativeness of station climate and tree-ring records as climate change indicators in the Upper Indus Basin. In: Talk presented at International Conference/Workshop on Dendrochronology held at Federal Urdu University, Karachi, November 15, 2010.

Archer, D., Fowler, H.J., 2004. Spatial and temporal variations in precipitation in the Upper Indus Basin, global teleconnections and hydrological implications. Hydrol. Earth Syst. Sci. 8 (1), 47-61.

Armstrong, R., 2010. The glaciers of the Hindu Kush-Himalayan Region: a summary of the science regarding glacier melt/retreat in the Himalayan, Hindu Kush, Karakoram, Pamir, and Tien Shan mountain ranges. ICIMOD, Kathmandu, 20pp.

Bolch, T., Kulkarni, A., Kääb, A., Huggel, C., Paul, F., Cogley, J.G., Frey, H., Kargel, J.S., Fujita, K., Scheel, M., Bajracharya, S., Stoffel, M., 2012. The state and fate of Himalayan glaciers. Science 336 (6079), 310-314.

Bookhagen, B., Burbank, D.W., 2010. Toward a complete Himalayan hydrological budget: spatiotemporal distribution of snowmelt and rainfall and their impact on river discharge. Journal of Geophysical Research. vol. 115. (F03019) doi: 10.1029/2009JF001426.

Chow, V.T., Maidment, D.R., Mays, L.W., 1988. Applied Hydrology. McGraw Hill Book Company, ISBN 0-07-010810-2. 572pp.

Cleaveland, M.K., 1999. A 963-year reconstruction of summer (JJA) streamflow in the White River, Arkansas, USA, from tree-rings. The Holocene 10, 33-41.

Cook, E.R., Jacoby, G.J., 1983. Potomac River streamflow since 1730 as reconstructed by tree rings. J. Climate Appl. Meteorol. 22, 1659-1672.

Cook, E.R., Johnson, A.H., 1989. Climate change and forest decline: a review of the red spruce case. Water Air Soil Pollut. 48, 127-140.

Cook, E.R., Kairiukstis, L., 1990. Methods of Dendrochronology. Kluwer, Dordrecht, 406pp.

Cook, E.R., Peters, K., 1981. The smoothing spline: a new approach to standardizing forest interior tree-ring width series for dendroclimatic studies. Tree-Ring Bull. $41,45-53$

Cook, E.R., Briffa, K.R., Meko, D.M., Graybill, D.S., Funkhouser, G., 1995. The 'segment length curse' in long tree-ring chronology development for paleoclimatic studies. Holocene 5, 229-237.

Cook, E.R., Meko, D.M., Stahle, D.W., Cleaveland, M.K., 1999. Drought reconstructions for the continental United States. J. Clim. 12, 1145-1162.
Cook, E.R., D’Arrigo, R.D., Mann, M.E., 2002. A well-verified, multiproxy reconstruction of the winter North Atlantic oscillation index since AD 1400. J. Clim. 15, 1754-1764

Cook, E.R., Woodhouse, C., Eakin, C.M., Meko, D.M., Stahle, D.W., 2004 Long-term aridity changes in the western United States. Science 306, 10151018.

Cook, E.R., Anchukaitis, K.J., Buckley, B.M., D’Arrigo, R.D., Jacoby, G.C., Wright, W.E., 2010a. Asian monsoon failure and megadrought during the last millennium. Science 328 (5977), 486-489.

Cook, E.R., Seager, R., Heim, R.R., Vose, R.S., Herweijer, C., Woodhouse, C.W., 2010b. Megadroughts in North America: placing IPCC projections of hydroclimatic change in a long-term paleoclimate context. J. Quat. Sci. 25 (1), 48-61.

Crutzen, P.J., 2002. Geology of mankind. Nature 415, 23.

Efron, B., 1979. Bootstrap methods: another look at the jackknife. Ann. Stat. 7, 1-26. Esper, J., 2000. Long term tree-ring variations in junipers at the upper timberline in the Karakorum (Pakistan). The Holocene 10, 253-260.

Esper, J., Bosshard, A., Schweingruber, F.H., Winiger, M., 1995. Tree-rings from the upper timberline in the Karakorum as climatic indicators for the last 1000 years. Dendrochronologia 13, 79-88.

Esper, J., Frank, D.C., Wilson, R.J.S., Buentgen, U., Treydte, K., 2007. Uniform growth trends among central Asian low- and high-elevation juniper tree sites. Trees 21 $141-150$.

Fowler, H.J., Archer, D.R., 2006. Conflicting signals of climate change in the Upper Indus Basin. J. Clim. 19 (17), 4276-4293.

Fritts, H.C., 1976. Tree Rings and Climate. Academic Press, New York, 567pp.

Gardelle, J., Berthier, E., Arnaud, Y., 2012. Slight mass gain of Karakoram glaciers in the early 21st century. Nat. Geosci. 5, 322-325.

Gove, J.M., 1988. The Little Ice Age. Methuen, London and New York, 498 pp.

Hegerl, G.C., Crowley, T.J., Allen, M., Hyde, W.T., Pollack, H.N., Smerdon, J., Zorita, E., 2007. Detection of human influence on a new, validated 1500 -year temperature reconstruction. J. Clim. 20, 650-666.

Hewitt, K., 2005. The Karakoram anomaly? Glacier expansion and the 'elevation effect', Karakoram, Himalaya. Mount. Res. Develop. 25 (4), 332-340.

ICIMOD, 2010. Islamic Republic of Pakistan: Glacial Melt and Downstream Impacts on Indus Dependent Water Resources and Energy. Technical Assistance Consultant's Report for the Asian Development Bank, Project Number RETA6420. 50pp.

Immerzeel, W.W., Droogers, P., de Jong, S.M., Bierkens, M.F.P., 2009. Large-scale monitoring of snow cover and runoff simulation in Himalayan river basins using remote sensing. Remote Sens. Environ. 113, 40-49.

Immerzeel, W.W., van Beek, L.P.H., Bierkens, M.F.P., 2010. Climate change will affect the Asian water towers. Science 328, 1382-1385.

Meko, D.M., 1997. Dendroclimatic reconstruction with time varying subsets of tree indices. J. Clim. 10, 687-696.

Meko, D., Woodhouse, C.A., Baisan, C.A., Knight, T., Lukas, J.J., Hughes, M.K., Salzer M.W., 2007. Medieval drought in the upper Colorado River Basin. Geophys. Res. Lett. 34 (L10705) doi: 10.1029/2007GL029988.

Melvin, T.M., Briffa, K.R., 2008. A "signal-free" approach to dendroclimatic standardisation. Dendrochronologia 26 (2), 71-86.

Michaelsen, J., 1987. Cross validation in statistical climate forecast models. J. Climate Appl. Meteorol. 26, 1589-1600.

Olive, D.J., 2007. Prediction intervals for regression models. Comput. Stat. Data Anal. 51, 3115-3122.

Pellicciotti, F., Buergi, C., Immerzeel, W.W., Konz, M., Shrestha, A.B., 2012 Challenges and uncertainties in hydrological modeling of remote Hindu Kush-Karakoram-Himalayan $(\mathrm{HKH})$ basins: suggestions for calibration strategies. Mount. Res. Develop. 32 (1), 39-50.

Picard, R.R., Berk, K.N., 1990. Data splitting. Am. Stat. 44 (2), 140-147.

Qureshi, A.S., 2011. Water management in the Indus Basin in Pakistan: challenges and opportunities. Mount. Res. Develop. 31 (3), 252-260.

Rango, A., Salomonson, V.V., Foster, J.L., 1977. Seasonal streamflow estimation in the Himalayan region employing meteorological satellite snow cover observations. Water Resour. Res. 13 (1), 109-112. http://dx.doi.org/10.1029/ WR013i001 p00109.

Rodriguez-Iturbe, I., 1969. Estimation of statistical parameters for annual river flows. Water Resour. Res. 5 (6), 1418-1421.

Schmidt, S., Nusser, M., 2009. Fluctuations of Raikot Glacier during the past 70 years: a case study from the Nanga Parbat massif, northern Pakistan. J. Glaciol. 55 (194), 949-959.

Seber, G.A.F., Lee, A.J., 2003. Linear Regression Analysis, second ed. Wiley, New York, 557pp.

Sharif, M., Archer, D.R., Fowler, H.J., Forsythe, N., 2012. Trends in timing and magnitude of flow in the Upper Indus Basin. Hydrol. Earth Syst. Sci. Discuss. 9 9931-9966.

Shekhar, M.S., Chand, H., Kumar, S., Srinivasan, K., Ganju, A., 2010. Climate change studies in the western Himalaya. Ann. Glaciol. 51 (54), 105-112.

Snee, R.D., 1977. Validation of regression models: methods and examples. Technometrics 19, 415-428.

Stockton, C.W., Jacoby, G.C., 1976. Long-term surface-water supply and streamflow trends in the Upper Colorado River Basin. Lake Powell Research Project Bulletin 18, National Science Foundation, Arlington, Va. 70pp.

Stokes, M.A., Smiley, T.L., 1968. An Introduction to tree-ring dating. The University of Chicago Press, Chicago, 73pp.

Treydte, K.S., Schleser, G.H., Helle, G., Frank, D.C., Winiger, M., Haug, G.H., Esper, J. 2006. The 20th century was the wettest period in northern Pakistan over the past millennium. Nature 440, 1179-1182. 
Vinod, H.D., 2006. Maximum entropy ensembles for time series inference in economics. J. Asian Econom. 17 (6), 955-978.

Vinod, H.D., 2010. A New Solution to Time Series Inference in Spurious Regression Problems. Discussion Paper No: 2010-01, Department of Economics, Fordham University, NY. 37 pp.

Vinod, H.D., López-de-Lacalle, J., 2009. Maximum entropy bootstrap for time series: the meboot R package. J. Stat. Softw. 29 (5), 1-19.

Visser, H., Molenaar, J., 1988. Kalman filter analysis in dendroclimatology. Biometrics 44, 929-940.

Weisberg, S., 2005. Applied Linear Regression, third ed. John Wiley, New Jersey, 310pp.

Wilks, D.S., 1997. Resampling hypothesis tests for autocorrelated fields. J. Clim. 11, 65-82.
Wilson, R., Wiles, G., D’Arrigo, R., Zweck, C., 2007. Cycles and shifts: 1300-years of multi-decadal temperature variability in the Gulf of Alaska. Climate Dyn. 28, 425-440.

Winiger, M., Gumpert, M., Yamout, H., 2005. Karakorum-Hindukush-western Himalaya: assessing high-altitude water resources. Hydrol. Process. 19 (12), 2329-2338.

Woodhouse, C.A., Gray, S.T., Meko, D.M., 2006. Updated streamflow reconstructions for the Upper Colorado River Basin, Water Resour. Res. 42 (W05415). doi: 10.1029/2005WR004455.

World Bank, 2005. Pakistan Country Water Resources Assistance Strategy. Water Economy: Running Dry. Report no. 34081-PK, South Asia Region. 145pp. 